Science, Technology and Development 34 (2): 109-113, 2015

ISSN 0254-6418 / DOI: 10.3923/std.2015.109.113

(C) 2015 Pakistan Council for Science and Technology

\title{
Characterization of Toxic Metals Adsorption Isotherms on Activated Carbon Using Locally Design Jar Test Apparatus
}

\author{
${ }^{1}$ Zulfiqar Ahmad Bhatti, ${ }^{2}$ Farhana Maqbool, ${ }^{3}$ Sadia Qayyum, ${ }^{4}$ Javeria Farooq, \\ ${ }^{3}$ Romana Manzor and ${ }^{3}$ Yang-Guo Zhao \\ ${ }^{1}$ Department of Environmental Sciences, COMSATS Institute of Information Technology, \\ Abbottabad, 22060, Pakistan \\ ${ }^{2}$ Department of Microbiology, Hazara University, Garden Campus, Mansehra, 21300, Pakistan \\ ${ }^{3}$ College of Environmental Science and Engineering, Ocean University of China, Qingdao, 266100, China \\ ${ }^{4}$ Department of Zoology, Hazara University, Garden Campus, Mansehra, 21300, Pakistan
}

\begin{abstract}
Toxic metals are present as micropollutants in the water bodies, which are difficult to remove. In the present study 4 different metals ( $\mathrm{Cd}, \mathrm{Cu}, \mathrm{Pb}$ and $\mathrm{As}$ ) adsorption on activated carbon was performed. For this purpose new jar test apparatus was manufactured. The removal efficiency of these metals was checked by applying different adsorption isotherm. The Langmuir showed single layer adsorption while, Freundlich and Brunaur-Emmet-Teller (BET) isotherms showed multi layer of metals molecules on activated carbon. Different metal concentrations were used as 5, 10 and $15 \mathrm{mg} \mathrm{L}^{-1}$ and the comparative adsorption isotherm showed the removal rate of metals were as $\mathrm{Cd}>\mathrm{Cu}>\mathrm{Pb}>\mathrm{As}$ at $15 \mathrm{mg} \mathrm{L}^{-1}$ concentration. Cadmium followed the BET isotherm which indicated multilayer adsorption on activated carbon while $\mathrm{As}, \mathrm{Cu}$ and $\mathrm{Pb}$ showed single layer adsorption. It is concluded from the result that activated carbon is the promising technique for the removal of $\mathrm{Cd}$ and to certain extend for $\mathrm{Cu}$ and $\mathrm{Pb}$.
\end{abstract}

Key words: Activated carbon, adsorption isotherm, multilayer, langmuir

\section{INTRODUCTION}

The main threats to human health from heavy metals are associated with exposure to lead, cadmium, mercury and arsenic (Jarup, 2003). Cadmium occurs naturally in ores together with zinc, lead and copper. Cadmium compounds are used as color pigment, several alloys and now most commonly in re-chargeable nickel-cadmium batteries. The general population is exposed to these toxic metals from air and food in roughly equal proportions (WHO, 1995). Inorganic arsenic is present in groundwater used for drinking in several countries all over the world (e.g. Bangladesh, Chile and China), whereas organic arsenic compounds such as arsenobetaine are primarily bio-accumulating in fish which thus transfer to human. Arsenic concentrations in blood, hair, nails and urine have been used as biomarkers of exposure (WHO, 2001). Copper is an essential trace element that is vital to the health of all living things. The human body has complex homeostatic mechanisms which attempt to ensure a constant supply of available copper, while eliminating excess copper. However, like all essential elements and nutrients, too much or too little nutritional ingestion of copper can result in a corresponding condition of copper excess or deficiency in the body, each of which has its own unique set of adverse health effects (WHO, 2001).

The commonly used procedures for removing metal ions from aqueous streams include chemical precipitation, lime coagulation, ion exchange, reverse osmosis, solvent extraction (Benefield et al., 1982) and activated carbon. Activated carbon is a black solid material like powdered charcoal (Abdullah et al., 2001), which processed to be riddled with small, low-volume pores that increase the surface area available for adsorption or chemical reactions (Martin and Ng, 1987).

Several mathematical relationships have been developed to describe the equilibrium distribution of solute solid and liquid phases and thus aid in the interpretation of adsorption data. The Langmuir, Freundlich and Brunaur-Emmet-Teller (BET) isotherm (Abdullah et al., 2001) are used to study the adsorption. Langmuir's isotherm is based on the assumption that points of valency exist on the surface of the adsorbent and that each of these sites is capable of adsorbing one molecule; thus, the adsorb layer will be one molecule thick. Clay minerals followed Langmuir and/or Freundlich type models, corresponding to monolayer binding of metal ions on a homogeneous adsorbent surface. Isotherms for 
the fungi were non-Langmuir types, better fits the BET model for multi-layer adsorption onto non-homogeneous surfaces (Morley and Gadd, 1995). Furthermore, it is assumed that all the adsorption sites have equal affinities for molecule of adsorbate that the presence of adsorbed molecules at one site will not affect the adsorption of molecule on adjacent site (Abdullah et al., 2001). Brunauer, Emmett and Teller (BET) isotherm based on the assumption that molecules could be adsorbed more than one layer thick on the surface of adsorbent. The adsorbent surface is composed of uniform, localized sites and the adsorption at one site does affect the adsorption on neighboring sites.

The main objective of present study was to examine the adsorption isotherm characteristics of $\mathrm{Pb}, \mathrm{Cu}, \mathrm{Cd}$ and As on activated carbon from water.

\section{MATERIALS AND METHOD}

Jar test apparatus manufacturing: Locally designed stainless steel jar test apparatus constructed by Sorgos Compress Hattar was used with variable speed from 20-500 rpm. It was built by using four 6.5 inches long iron shaft of $1 \mathrm{~cm}$ diameter, one $3.3 \mathrm{~cm}$ long blade was attach to each rod. First rod attached with gear made up of Teflon which was operated by motor at the top of apparatus. During operation the first gear rotate other 3 gears attached with their respective shafts (Fig. 1).

Activated carbon was purchased from local company Water 2000 pvt limited Lahore Pakistan and manufactured by Norit Nederland BV. It can be used in a large range of water applications including potable water and water treatment. It is produced by steam activation under the scope of CDX HACCP (Norit, 2012). The specification and general characteristics are shown in Table 1.

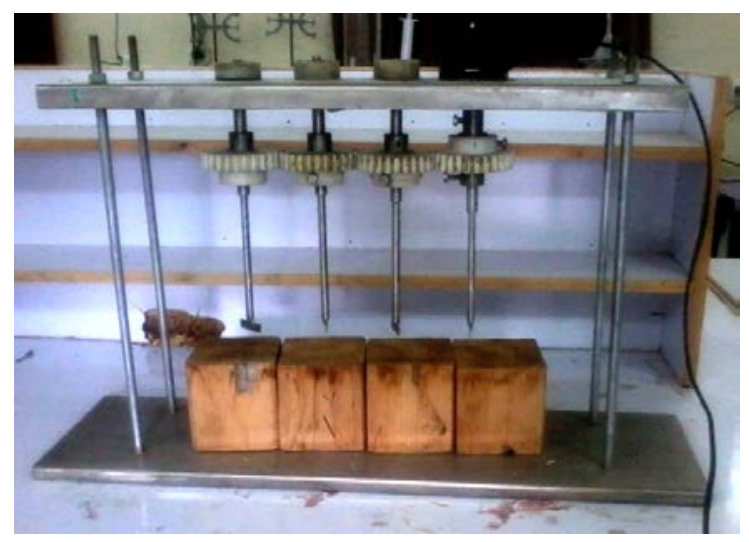

Fig. 1: Jar test apparatus having 4 shafts attached with frame, first shaft attached with gear and then motor which run this apparatus
The surface area was 5-1000 $\mathrm{m}^{2}$ and about 2-4 mm in size for $1 \mathrm{~g}$ of activated carbon. The $\mathrm{pH}$ meter HANNA, HI-991003 was used for $\mathrm{pH}$ determination. In adsorption study, standards stock solutions of different concentration of heavy metal ( $\mathrm{Pb}, \mathrm{Cu}, \mathrm{Cd}$ and $\mathrm{As}) 5,10$ and $15 \mathrm{mg} \mathrm{L}^{-1}$ were prepared. These different metal concentrations of aqueous solution of $200 \mathrm{~mL}$ were treated with $400 \mathrm{mg}$ of activated carbon separately for $120 \mathrm{~min}$ at $170 \mathrm{rpm}$ each. Samples were collected after every $30 \mathrm{~min}$ (Benefield et al., 1982). The amount of metal adsorption on activated carbon was detected with atomic absorption spectroscopy by adopting the method of Maqbool et al. (2011).

\section{RESULTS AND DISCUSSION}

Arsenic removal: Results obtained from the atomic adsorption showed that arsenic was continuously decreasing with time as the adsorption process continues in jar test apparatus. The $\mathrm{pH}$ was ranged between 4-5 of all samples. Temperature was in the range between $18-23^{\circ} \mathrm{C}$.

Langmuir isotherm was applied on different arsenic concentration. There was a constant decrease in the arsenic concentration $\left(15 \mathrm{mg} \mathrm{L}^{-1}\right)$ through out the adsorption on activated carbon. Slope of Langmuir isotherm showed that there was single layer adsorption of arsenic and linear track result when the quantity $1 /(\mathrm{x} / \mathrm{m})$ was plotted against 1/C (Martin and Ng, 1987).

The $10 \mathrm{mg} \mathrm{L}^{-1}$ of arsenic also formed a single layer adsorption on the activated carbon. Chemical adsorption occur through out the sides and corner of the adsorbent, since these sites were characterized by presence of various functional groups which participate in adsorption through electron sharing reaction (Martin and Ng, 1987).

The size of carbon particle influences the rate of adsorption, which increased as the particle size decreased. Almost, same behavior of adsorption was observed in Fig. 2a-c, but adsorption rate are more during first $30 \mathrm{~min}$.

Lead removal: Results through atomic adsorption showed continuous decrease in lead in samples with

\begin{tabular}{|c|c|}
\hline Parameters & Extent \\
\hline \multicolumn{2}{|l|}{ Specification (maximum) } \\
\hline Particle size > 3.15 mm (mass \%) & 10 \\
\hline Particle size <0.71 mm (mass \%) & 5 \\
\hline \multicolumn{2}{|l|}{ General characteristics } \\
\hline Apparent density $\left(\mathrm{kg} \mathrm{m}^{-1}\right)$ & 290 \\
\hline Density backwashed and drained $\left(\mathrm{kg} \mathrm{m}^{-3}\right)$ & 255 \\
\hline Effective size $\mathrm{D}_{10}$ & 1.2 \\
\hline Ash content (mm) & 8 \\
\hline $\mathrm{pH}$ & Alkaline \\
\hline
\end{tabular}


Sci. Technol. Dev., 34 (2): 109-113, 2015
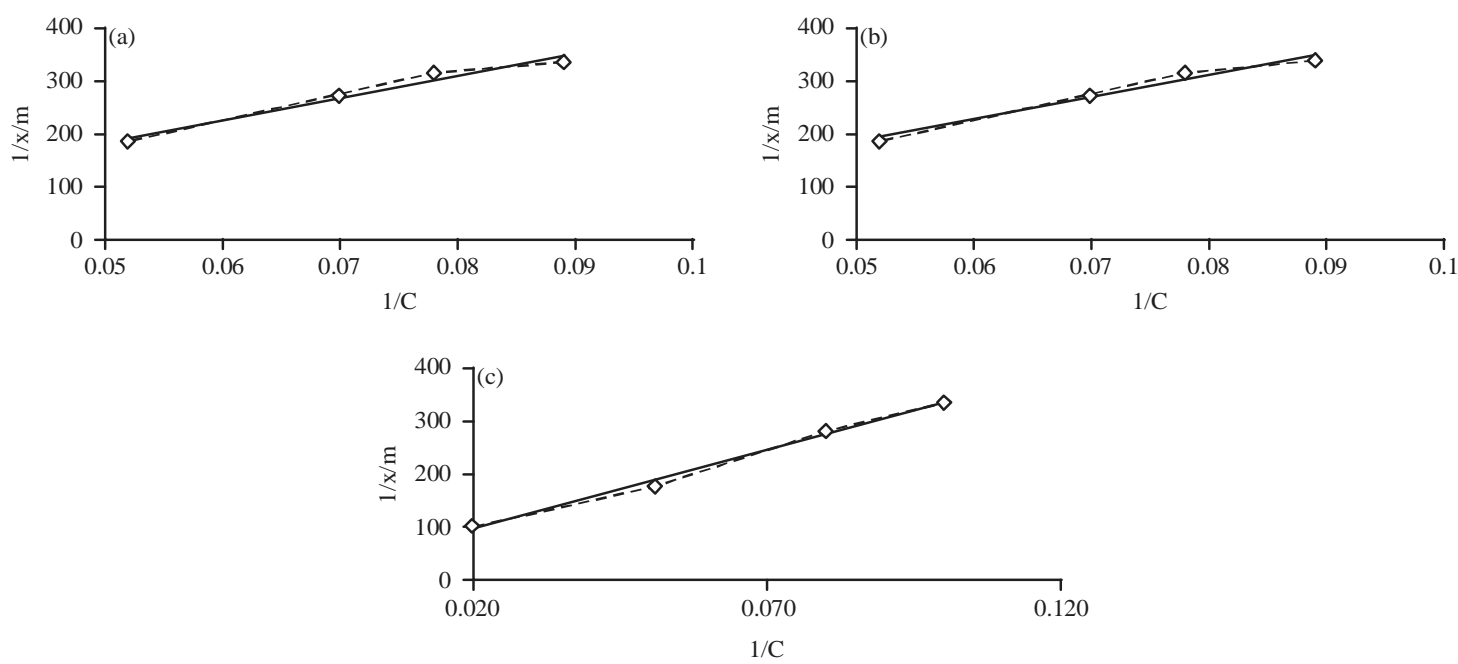

Fig. 2(a-c): Arsenic Langmuir isotherms, (a) 15, (b) 10 and (c) 5 mg L ${ }^{-1}$
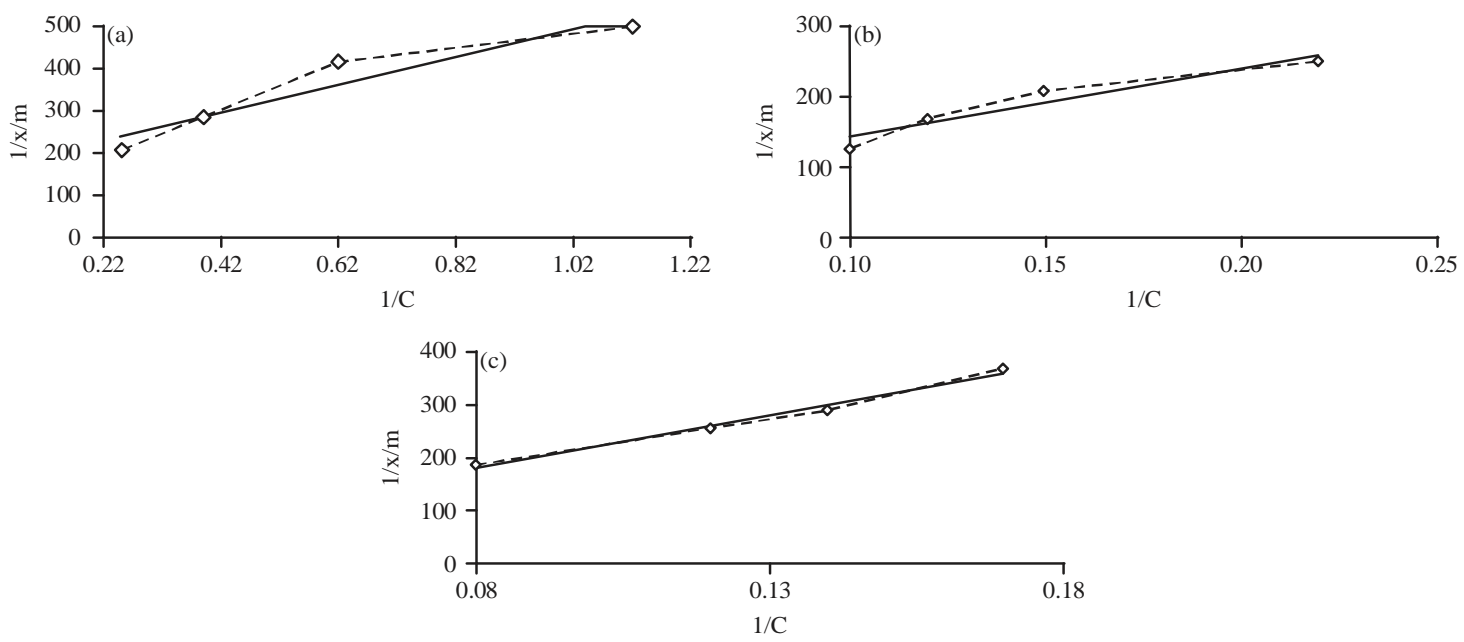

Fig. 3(a-c): Lead Langmuir isotherms, (a) 15, (b) 10 and (c) 5 mg L ${ }^{-1}$

increasing the time of adsorption on jar test apparatus at $170 \mathrm{rpm}$. The $\mathrm{pH}$ was ranged between 4-5 of all samples. Temperature was ranges between $18-23^{\circ} \mathrm{C}$. Langmuir isotherm equation was applied to the results and there were constant slopes which shows that $\mathrm{Pb}$ also formed a single layer on activated carbon.

Lead also showed a constant decline at different concentrations (Fig. 3a-c) during adsorption through activated carbon and follow the Langmuir isotherm and form a single layer adsorption. Although in Fig. 3a showed small curve on third reading but it is acceptable in term of adsorption because such fluctuation mostly occur in experiment due to certain contamination (Martin and Ng, 1987).

Lead showed constant decline upto $90 \mathrm{~min}$, after that there was a reduction in rate of absorption on activated carbon, single layer might be developed on adsorbent was noted as lead follow the Langmuir isotherm. The majority of the molecules were adsorbed onto the large surface area within the pores of carbon particles and relatively few were adsorbed on the outside surface of particle (Martin and Ng, 1987).

Figure 3 showed that lower concentration of lead form a single layer absorption on specific $\mathrm{pH}$ and room temperature. Increase in $\mathrm{pH}$ and temperature cause reduction in the absorption of lead and other metals (Martin and Ng, 1987) (Fig. 4a-c).

Cadmium removal: Cadmium was the only compound in present study that showed a multiple layer adsorption on the adsorbent. Its multiple layer adsorptions showed that cadmium can accumulate more at the activated 
Sci. Technol. Dev., 34 (2): 109-113, 2015
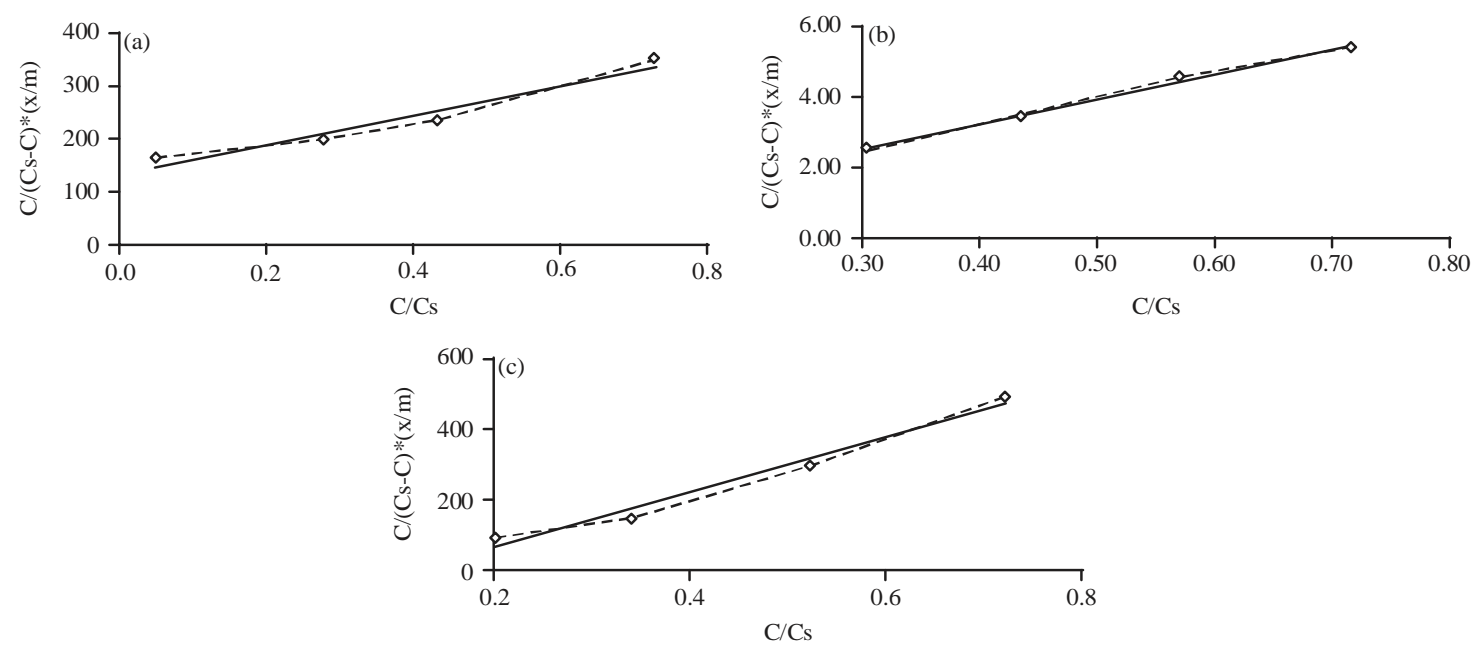

Fig. 4(a-c): Cadmium Langmuir isotherms, (a) 15, (b) 10 and (c) 5 mg L ${ }^{-1}$
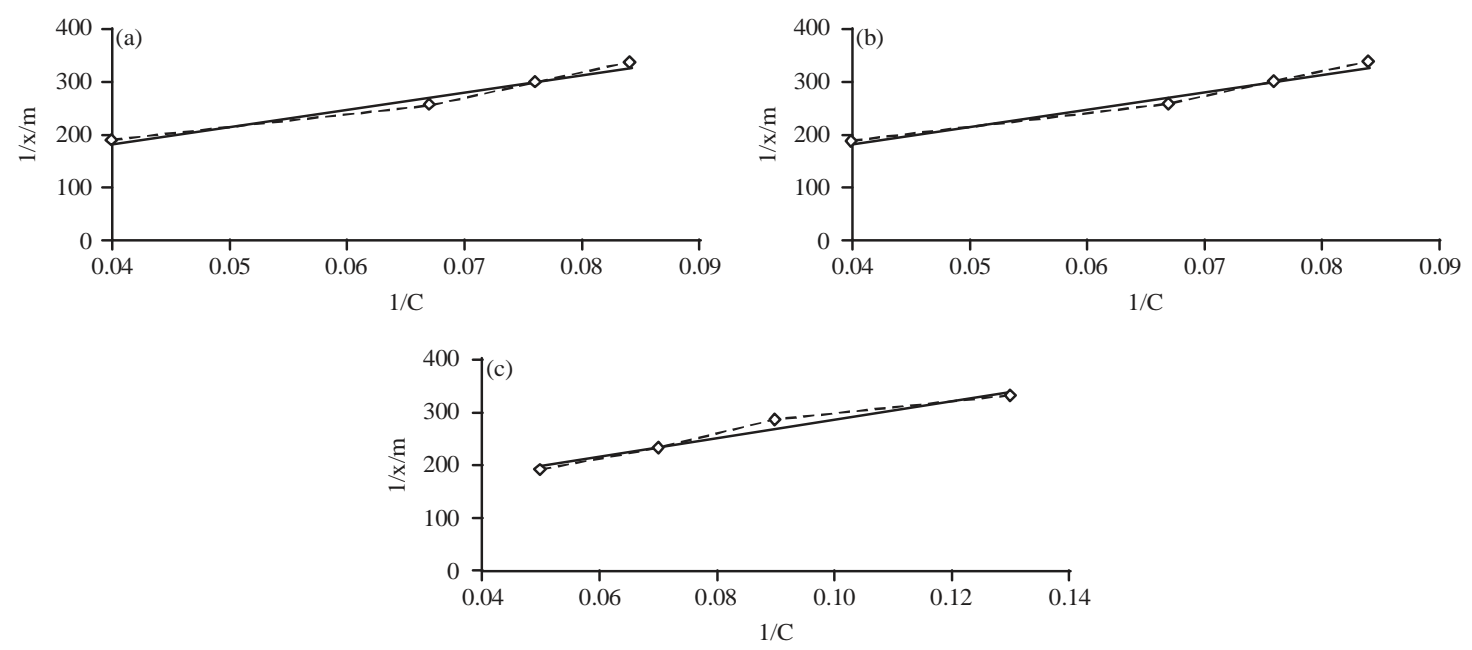

Fig. 5(a-c): Copper Langmuir isotherms, (a) 15, (b) 10 and (c) 5 mg L ${ }^{-1}$

carbon and this adsorbent was a good material for cadmium. It followed the BET isotherm forming multiple layer adsorptions. As, experiment was conducted on the room temperature and acidic $\mathrm{pH}$, the increase in temperature and $\mathrm{pH}$ reduced the $\mathrm{Cd}$ adsorption on the activated carbon.

Each concentration taken for adsorption shows a gradual decrease in cadmium concentration which shows that each concentration had a multiple layered adsorption. This was because of attraction between carbon particles and Cd species.

The BET isotherm was followed by cadmium as it had multiple adsorption and linear graph formation. This was because activated carbon has more attraction toward the cadmium also it can be assumed the cadmium had physical absorption rather than chemical adsorption.
Copper removal: Constant linear slope in Fig. 5a-c showed a single layer adsorption of copper on activated carbon following the Langmuir isotherms. Each sample taken after $30 \mathrm{~min}$ between $2 \mathrm{~h}$ shows a constant reduction in $\mathrm{Cu}$ concentration. Single layer adsorption means less attraction towards the adsorbent and more towards the solution in which specific solutes were present. Since, adsorption is the surface phenomenon, the large surface area of activated carbon helps to adsorb better.

Most waste water contains a mixture of compounds representing many different sizes of molecules. In this situation, large molecules blocking the pores to prevent the entrance of small molecules. However, the irregular shape of both the molecules and the pores prevents such blockage. Furthermore, the greater mobility 
Sci. Technol. Dev., 34 (2): 109-113, 2015

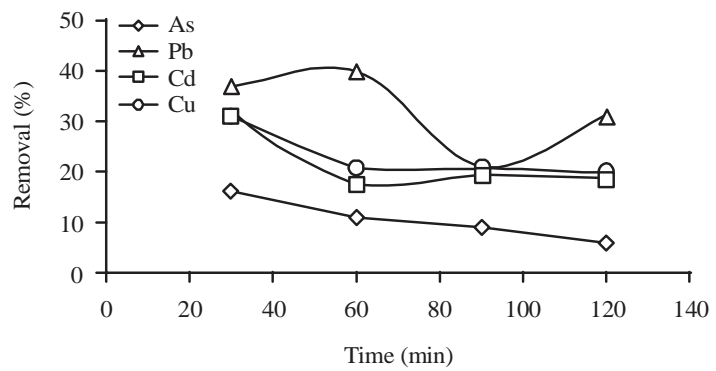

Fig. 6: Percentage removal of metals at different time period

Table 2: Metals removal percentage

\begin{tabular}{lllll}
\hline & Removal (\%) & & \\
Time (min) & As & Pb & Cd & Cu \\
\hline 30 & 16 & 31.0 & 37 & 31 \\
60 & 11 & 17.6 & 40 & 21 \\
90 & 9 & 19.5 & 21 & 21 \\
120 & 6 & 18.5 & 31 & 20 \\
\hline
\end{tabular}

of small molecules allows them to diffuse faster and to enter the pores ahead of the large molecules (Benefield et al., 1982). In physical adsorption as the molecules entered into the pores of the carbon particles it was attached to the particles for its removal from the solution.

Percentage removal of different metals: According to Fig. 6, Cd maximum removal rate of $40 \%$ was observed at 60 min while other metals maximal removal rate was in order of $\mathrm{Cu}=\mathrm{Pb}>\mathrm{As}$ at $30 \mathrm{~min}$. The highest $\mathrm{Cd}$ removal in comparatively longer time was due to its multi layer adsorption which was confirmed by applying BET adsorption isotherm. After sharp decrease in Cd metals at 90 min again removal rate decrease to $21 \%$. The reason might be the physical forces from jar test apparatus which disturbed the multi-layers of Cd species, further study is required to optimize the rpm to avoid detachments of $\mathrm{Cd}$ molecules from adsorbent. The removal of $\mathrm{Cu}$ and $\mathrm{Pb}$ was showing same pattern with the passage of time but $\mathrm{Cu}$ showed more removal than $\mathrm{Pb}$ which was in accordance with Faur-Brasquet et al. (2002) (Table 2).

In first 30 min maximum removal rate of $31 \%$ was observed this indicates that AC can successfully remove $\mathrm{Cu}$ and $\mathrm{Pb}$ in 30 min as the surface of activated $\mathrm{C}$ occupied with single layer of molecules then no empty place was left which might remove some more metal ions. Arsenic showed lesser removal rate of $16 \%$ after 30 min which gradually decreased to $6 \%$ at $120 \mathrm{~min}$.

\section{CONCLUSION}

From overall adsorption study, we concluded that activated carbon removal rates were in the order of $\mathrm{Cd}>$ $\mathrm{Cu}>\mathrm{Pb}>\mathrm{As}$ at $15 \mathrm{mg} \mathrm{L}^{-1}$. Arsenic removal percentage was observed less than other metals. It was concluded that different metal maximum removal percentage was observed at different time of adsorption. For the removal of $\mathrm{Cu}, \mathrm{Pb}$ and $\mathrm{As}, 30$ min were sufficient to adsorb maximum on AC and these metals followed the Langmuir isotherm. Maximum removal of $\mathrm{Cd}$ was found after 60 min which followed BET isotherm.

\section{REFERENCES}

Abdullah, A.H., A. Kassim, Z. Zainal, M.Z. Hussien, D. Kuang, F. Ahmad and O.S. Wooi, 2001. Preparation and characterization of activated carbon from gelam wood bark (Melaleuca cajuputi). Malaysian J. Anal. Sci., 7: 65-68.

Benefield, L.D., J.F. Judkins and B.L. Weand, 1982. Fundamentals of Surface and Colloidal Chemistry. In: Process Chemistry for Water and Waste Water Treatment, Benefield, L.D., J.K. Judkins and B.L. Weand (Eds.). Prentice Hall, Inc., Englewood Cliffs, N.J., pp: 191-210.

Faur-Brasquet, C.F., Z. Reddad, K. Kadirvelu and P.L. Cloirec, 2002. Modeling the adsorption of metal ions $\left(\mathrm{Cu}^{2+}, \mathrm{Ni}^{2+}, \mathrm{Pb}^{2+}\right)$ onto ACCs using surface complexation models. Applied Sur. Sci., 196: 356-365.

Jarup, L., 2003. Hazards of heavy metal contamination. Br. Med. Bull., 68: 167-182.

Maqbool, F., Z.A. Bhatti, A.H. Malik, A. Pervez and Q. Mahmood, 2011. Effect of landfill leachate on the stream water quality. Int. J. Environ. Res., 2: 491-500.

Martin, R.J. and W.J. Ng, 1987. The repeated exhaustion and chemical regeneration of activated carbon. Water Res., 21: 961-965.

Morley, G.F. and G.M. Gadd, 1995. Sorption of toxic metals by fungi and clay minerals. Mycol. Res., 99: 1429-1438.

Norit, 2012. Norit electronic version. BV, Nijverheidsweg Noord 72, 3812 PM Amersfoort 2800 AC Amersfoort, The Netherland.

WHO., 1995. Lead Environmental Health Criteria. Vol. 165, World Health Organization, Geneva.

WHO., 2001. Arsenic and Arsenic Compounds. 2nd Edn., World Health Organization, Geneva. 